Running Head: NEGATIVE CONTACT AND OUTGROUP AVOIDANCE

When contact goes wrong: Negative intergroup contact

promotes generalized outgroup avoidance

Rose Meleady

Laura Forder

School of Psychology, University of East Anglia, UK. 


\begin{abstract}
This paper broadens our understanding of the consequences of negative intergroup contact. Study 1 reports cross-sectional evidence that negative contact with European immigrants in Britain is not only associated with increased prejudice, but also the avoidance of future contact with this group. Study $2 \mathrm{~A}$ and $2 \mathrm{~B}$ provided an experimental replication in a different intergroup context. A negative encounter with an outgroup member, but not an ingroup member, was found to reduce intentions to engage in contact with the outgroup in the future. Study 3 went on to demonstrate that the effect of negative contact on outgroup avoidance is not limited to the contacted outgroup, but is indirectly associated with reduced intentions to engage with other, secondary outgroups - an effect we refer to as an 'avoidance generalization effect'. Negative contact was also associated with lower general contact selfefficacy. Together, findings suggest that negative contact is damaging not just because it increases prejudice but also because it compromises future engagement with diversity.
\end{abstract}

KEYWORDS: intergroup contact, negative contact, prejudice, outgroup avoidance, secondary transfer effect 


\section{When contact goes wrong: Negative intergroup contact promotes generalized outgroup avoidance}

According to the Intergroup Contact Theory (Allport, 1954) prejudice between members of different groups can be reduced by encouraging positive interaction between them. This idea is supported by a wealth of research, including an extensive meta-analysis (Pettigrew \& Tropp, 2006). The contact effect replicates across different implementations, participant populations and bases for group membership (Al Ramiah \& Hewstone, 2013; Brown \& Hewstone, 2005). It is strengthened by certain 'optimal' conditions (e.g. equal status, cooperative norms, common goals and institutional support), but remains even in their absence (Pettigrew \& Tropp, 2006). While the beneficial effects of positive intergroup contact are now well established, we know less about the other side of the coin - what happens when contact goes wrong? This paper seeks to broaden our emerging understanding of the consequences of negative intergroup contact. Employing both cross-sectional and experimental designs we examine the impact of negative contact on outcomes associated with the avoidance of further cross-group interaction. We suggest that negative contact may be dangerous not only because it increases prejudice, but because it leads to the avoidance of future contact with the contacted outgroup as well as other, secondary outgroups.

\section{Negative Intergroup Contact}

In much of the existing literature the word 'contact' has been treated as synonymous with 'positive contact' or 'intergroup friendship' (Barlow et al., 2012). The emphasis on intergroup contact as a strategy to improve intergroup relations has understandably meant that research has focused on investigating the consequences of positive interactions across group lines (Pettigrew, 2008). Of course, in natural settings, intergroup contact is not always positive, but may be unpleasant or unfriendly. While the former can reduce prejudice, the 
latter may be expected to increase it. In their meta-analysis of over 500 contact studies, Pettigrew and Tropp (2006) observed that less than 5\% considered the effect of negativelytoned contact and its potential to disrupt the beneficial effects of positive contact.

An emerging body of research now addresses this gap in the literature. Barlow and colleagues (2012) were the first to simultaneously examine the effect of positive and negative contact on prejudice. As expected, positive contact was found to be negatively associated with prejudice, however this relationship was comparably weaker when negative contact was included in the analysis. In fact, negative contact was found to be more strongly associated with increased prejudice than positive contact was with its reduction. Graf, Paolini, and Rubin (2014) subsequently replicated these results when examining contact experiences across several European societies. The authors found that while people generally report less frequent negative contact than positive contact, negative contact emerged as a more robust and reliable predictor of prejudice (see also Dhont \& Van Hiel, 2009). This effect has been referred to a 'positive-negative valence asymmetry effect' (Barlow et al., 2012, see also Paolini, Harwood \& Rubin, 2010).

Other findings suggest to a more nuanced picture with the magnitude of negative contact effects depending on the methodological approach (e.g. Bekhuis, Ruiter, \& Coenders, 2013; Stark, Flache, \& Veenstra, 2013) and the outcome under consideration (e.g., Aberson, 2015, Hayward et al., 2017). Aberson (2015) for instance, found that positive and negative contact were similarly predictive of affective dimensions of prejudice, while negative contact was particularly important in explaining the cognitive dimensions of prejudice, such as stereotyping. Research has also explored the processes driving the effect of negative intergroup contact on prejudice. While some studies find negative contact to work via the same mediational pathways as positive intergroup contact, confirming or enhancing 
intergroup anxiety and perceptions of threat, and reducing empathy towards the outgroup (e.g. Aberson, 2015; Techakesari et al., 2015; Visintin, Voci, Pagotto, \& Hewstone, 2016), others argues that additional processes (e.g. intergroup anger) may also be important in explaining negative contact effects (e.g. Barlow et al., 2012; Hayward, Tropp, Hornsey, \& Barlow, 2017; Visintin, Green, Pereira, \& Miteva, 2017).

\section{Examining the Broader Consequences of Negative Contact}

The present research aimed to examine the influence of negative contact on outcomes beyond prejudice. Research on negative intergroup contact is still in its infancy and most of the work to date has employed measures of prejudice / outgroup evaluation as the principle outcome variable. In recent years however, scholars have emphasized the need to enlarge the pool of outcomes assessed in intergroup contact research to more fully capture its influencing beyond simply improving individuals' feelings towards others (e.g. Dixon, Levine, Reicher, Durrheim, 2012; Pettigrew \& Tropp, 2011; McKeown \& Dixon, 2017).

A particularly important area for attention is the impact of negative contact on what McKeown and Dixon (2017) refer to as “informal practices of social segregation” (p.3). A growing body of observational research that maps patterns of intergroup contact in social settings (e.g. classrooms and lecture theatres, nightclubs, canteens) demonstrates that even in the absence of structural barriers, individuals often voluntarily eschew intergroup encounters (e.g. Alexander \& Tredoux, 2010; Dixon \& Durrheim, 2003; Tredoux \& Dixon, 2009; Tredoux, Dixon, Underwood, Nunez, \& Finchilescu, 2005). As McKeown and Dixon (2017) note, factors leading to such practices are likely to include individuals' past experience of intergroup contact. Some evidence suggests that positive contact in one context at a given point in time tends to increase the likelihood that individuals will open themselves up to contact in other contexts and at other times (Braddock, 1980; Braddock, \& McParland, 1989). 
On the other hand, we may expect that negative contact experiences work in the opposite direction, creating a negative cycle of avoidance.

Some initial evidence supports this suggest. In their cross-sectional investigation, Barlow and colleagues (2012) found that while positive contact experience predicted intentions to interact again with the outgroup in the future, frequency of negative contact experience predicted greater prejudice and greater avoidance of the outgroup. Hayward and colleagues (2017) also provide some experimental evidence in a study that employed contact vignettes that described a contact scenario with a member of a fictional ethnic outgroup ('Broneans'). Participants who imagined a negative intergroup encounter subsequently rated themselves as less willing to engage in future contact with this group compared to both a positive and neutral contact condition. Other research also demonstrates how negative expectancies about interracial interactions can lead to a desire to avoid interacting with outgroup members (e.g., Plant \& Butz, 2006; Plant \& Devine, 2003; Tropp, 2003). Importantly, if negative contact not only increases prejudice, but also reduces individuals' willingness to interact again with the outgroup in the future then there is little chance of reconciliation or resolution between groups

The present research sought to add to the literature exploring how prior negative contact experiences may contribute to motivation to avoid the outgroup, and to extend these findings by examining whether avoidance may spread even beyond the encountered outgroup. Previous research has suggested that the attitudinal benefits of positive intergroup contact may extend beyond the encountered outgroup, to other outgroups not directly involved in the contact experience - an effect known as a 'Secondary Transfer Effect' (Pettigrew, 2009). Evidence of secondary transfer effects has been found in a range of intergroup contexts (for review see Lolliot et al., 2013). Pettigrew (2009) for instance, demonstrated that German 
citizens' contact with foreigners produced secondary reductions in prejudice towards homosexuals and homeless people. Similarly, contact between Catholics and Protestants in Northern Ireland has been shown to improve attitudes not just towards the religious outgroup, but also towards racial minority groups (Tausch et al., 2010).

The secondary transfer effects of intergroup contact occur via a process of 'attitude generalization' in which intergroup contact improves attitudes towards the primary outgroup, and these more positive attitudes then generalize to similar, secondary outgroups (Pettigrew, 2009; Tausch et al., 2010). Some emerging research has suggested that such attitude generalization effects may also occur for negative contact encounters (Brylka, JasinskajaLahti, \& Mähönen, 2016; Harwood, Paolini, Joyce, Rubin \& Arroyo, 2011). In the present research in we adopted a new outcome variable and aimed to explore whether such generalization effects may exist not just for attitudes, but also for outgroup avoidance. The effect of negative contact on outgroup avoidance may be expected to generalize beyond the contacted outgroup to increase avoidance with other, secondary outgroups. - a process we refer to as an 'avoidance generalization effect'. The emergence of such effects would suggest that negative contact is dangerous not just because it discourages future engagement with the outgroup with whom the encounter occurred, but because it encourages a more general retreat from contact.

\section{The Present Research}

Recent advancements in intergroup contact theory have highlighted the importance of recognising positive and negative contact experiences as related but separate dimensions of intergroup contact. While the relationship between negative contact and prejudice is now fairly well-established, less attention has been devoted to other outcomes of negative contact. In the present research we focus on the impact of negative contact on the avoidance of future 
intergroup encounters. Some emerging results suggest that negative contact may be damaging not just because it increases prejudice, but because it reduces the inclination to interact with members of the outgroup again in the future (Barlow et al., 2012; Hayward et al., 2017). We sought to replicate and extend these results. Study 1 involved an initial cross-sectional examination of the association between negative contact and outgroup avoidance. Study $2 \mathrm{~A}$ and $2 \mathrm{~B}$ sought to increase confidence in causal conclusions by providing the first experimental test of the impact of negative contact on outgroup avoidance in real-world intergroup context. Finally, in Study 3 we examined whether negative intergroup contact may extend even beyond the encountered outgroup to reduce intentions to engage in contact with other, secondary outgroup.

\section{Study 1}

Study 1 aimed to provide evidence of a cross-sectional association between negative intergroup contact and outgroup avoidance within a timely and important intergroup context. In June 2016, the British Government held a referendum to decide whether Britain should remain within, or leave the European Union (EU). Turnout was high with more than 30 million people voting. Of this, a majority voted to leave the EU. Debate surrounding the referendum focused heavily on immigration, and anti-immigrant attitudes were believed to play an important role in voting decisions (Meleady, Seger, \& Vermue, 2017). In this study, we examined British participants' experience of negative intergroup contact with EU immigrants and its association with prejudice and outgroup avoidance. Data was collected in January 2017, six months after the referendum. EU migration was still a very prominent topic at this time with the country experiencing a spike in racially motivated hate crimes following the referendum (BBC News, 2017).

\section{Participants}


Data was collected from a sample of 139 participants recruited from a UK University which included 128 females and 11 males, aged between 18 and 58. The sample size was determined on the basis of an a priori power analysis using $\mathrm{G}^{*}$ Power (Faul, Erdfelder, Buchner, \& Lang, 2009) which specified a minimum required sample of 108 to achieve $90 \%$ power to detect small-to-medium effects within a multiple regression analysis with two predictors (negative contact and positive contact). Due to the nature of the research question the study was only available to British respondents. Participants received partial course credit in exchange for their participation. No exclusions were made ${ }^{1}$.

\section{Method}

The study was described as a survey on current events. Quantity of negative intergroup contact, and quantity of positive intergroup contact were measured as two independent dimensions with measures adapted from Reimer et al., (2017). To measure negative intergroup contact, participants indicated how often they had had a variety of negative experiences with EU immigrants (from $1=$ never to 5 = very often), specifically: being verbally abused, intimidated, threatened with harm, ridiculed, and made to feel unwelcome $(\alpha=.87)$. We clarified that by 'EU immigrant' we meant someone who has come to live in Britain from another country within the EU. The order of all scales was counterbalanced across participants. To measure positive intergroup contact, participants indicated how often they had positive experiences with EU immigrants, including: being supported, helped, complimented, befriended, and made to feel welcome $(\alpha=.92)$.

Outgroup evaluation was measured with the General Evaluation Scale (Wright, Aron, McLaughlin-Vope, \& Ropp, 1997). Participants indicated their feelings towards EU immigrants, in general, on six bipolar scales (1- 7; warm-cold*, negative-positive, friendlyhostile*, suspicious-trusting, respect-contempt*, admiration-disgust*). Items marked with an 
asterisk were reverse scored, such that a higher score always indicated more positive outgroup evaluation $(\alpha=.93)$.

Outgroup avoidance with measured with two scales adapted from Barlow et al., (2012). These were active avoidance, measuring the desire to avoid face-to-face interactions with EU immigrants, and issue avoidance, measuring the avoidance of sensitive intergroup topics in discussions with EU immigrants. To measure active avoidance, participants indicated their agreement with three statements: "I would rather spend my lunch time alone than sit with a group of EU immigrants", "I would be comfortable being asked to work in a group which included EU immigrants*" and "I would rather listen to a lecture on the EU referendum than speak to an EU immigrant on my course". Answers were coded such that higher scores indicated greater avoidance (from $1=$ strongly disagree to $7=$ strongly agree) Together, the items formed a reliable scale $(\alpha=.70)$. Issue avoidance was also measured with three items on the same scale; "I would avoid talking about access to public services (e.g. housing, welfare benefits) with EU immigrants", "I would be comfortable talking about immigration laws with EU immigrants*", and "I would go out of my way to avoid talking about the EU referendum with EU immigrants* $(\alpha=.79)$.

Finally, as more of an exploratory variable, we also examined how positive and negative contact may predict the recognition of intergroup discrimination. Participants were asked to indicate the extent to which they believed EU immigrants experience discrimination from the police, in the workforce, from fellow employees, from teachers and educators, in the form of racially motivated glaring, and in the form of racial slurs (from $1=$ never, to $6=$ very often; Todd, Bodenhausen, \& Galinsky, 2012). For ease of interpretation all items were reversed scored such that higher scores corresponded to greater denial of discrimination ( $\alpha$ $=.79)$. 


\section{Results and Discussion}

Descriptive statistics for, and bivariate correlations between all variables are reported in Table $1^{2}$. A paired samples $t$-test indicated that people experienced more positive intergroup contact with EU immigrants more frequently $(M=3.41, S D=0.89)$ than negative intergroup contact $(M=1.67, S D=0.76), t(139)=15.29, p<.001, d=1.30$.

\section{[insert Table 1 here]}

Next, we conducted a series of regressions to allow us to examine the independent effect of negative contact while controlling for positive contact experience. Table 2 displayed the model statistics and coefficients testing the independent predictive power of negative and positive contact on all dependent variables.

\section{[insert Table 2 here]}

Together, negative and positive contact accounted for a significant amount of variance in outgroup evaluation. Both types of contact also had significant independent effects on this variable. As can be seen, the more negative contact participants reported with EU immigrants the lower their evaluations were of this group $(\beta=-.31, p<.001)$. The more positive contact they reported, the higher their evaluation of the group $(\beta=.43, p<.001)$.

The model also accounted for a significant amount of variance in both types of outgroup avoidance. Negative contact was positively associated with both active $(\beta=.30, p<$ $.001)$, and issue avoidance $(\beta=.22, p=.005)$, while positive contact was negatively associated with both active $(\beta=-.22, p=.008)$ and issue avoidance $(\beta=-.42, p<.001)$. 
Finally, although the overall model only reached marginal significance for denial of discrimination, interestingly, we find that while there is no association with positive contact $(\beta=-.01, p=.938)$, the more negative contact participants reported having with EU immigrants, the more they denied that this group were targets of discrimination $(\beta=.20, p=$ $.027)$.

Study 1 aimed to provide initial evidence of an association between negative intergroup contact and outgroup avoidance. Results replicate the findings of Barlow et al., (2012) in a new intergroup context. In data collected shortly after the EU referendum in Britain we find that individuals' experience of negative contact with EU immigrants is not only associated with increased prejudice, but also with a reluctance to engage in future interactions with this group whether this be the active avoidance of face-to-face contact with immigrants, or the avoidance of sensitive intergroup topics in discussions with them. Interestingly, negative intergroup contact was also found to be uniquely associated with denial of discrimination. The more negative contact individuals had experienced with EU immigrants, the less likely they were to recognise instances of discrimination against this group. Taken together, findings suggest that following negative intergroup contact, individuals may close themselves off to future intergroup encounters and to the reality of the inequality of intergroup relations.

\section{Study 2}

Study 1 provides cross-sectional evidence that negative contact experiences may encourage people to close themselves off to future outgroup contact. The data is however, cross-sectional and thus we cannot determine causal relationships between contact and outgroup avoidance. Hayward and colleagues (2017) provide some initial experimental evidence for the impact of negative intergroup contact on outgroup avoidance. However, this 
study was limited to an imagined, scenario-based paradigm that described a contact experience with a fictional outgroup. In two studies - Study 2A and Study 2B - we sought to replicate this effect in a real intergroup context. We experimentally manipulated negative contact experience within the context of an economic game. Economic games allow us to model a situation of interdependence between decision-makers such that the choices of both parties determine the distribution of valued resources. In this case, participants believed they were playing an economic game with an outgroup member, and responses were preprogrammed to allow us to experimentally manipulate a non-cooperative intergroup encounter.

\section{Study 2A}

\section{Participants}

Data was collected from a sample of 92 undergraduate participants from a UK university. Because of the experimental paragraph was novel, effect sizes could be estimated in advance. We aimed to collect data until we reached a target sample size of 100 participants, or until the end of the semester, whichever came first. The target outgroup in this study was Chinese people and data from 7 participants has to be removed because they identified as South Asian or mixed ethnicity. Following exclusions, the final sample size for analysis was 81 which included 9 males and 72 females, aged between 18 and 50 years old. Participants were randomly assigned to either the negative outgroup contact condition $(n=$ $41)$ or a neutral contact control condition $(n=40)$. A power analysis indicates that this sample size yields reasonable power (.60) for detecting a medium effect size $(d=.50)$ in pairwise comparisons.

\section{Method}


Participants reported to the laboratory to take part in a study on decision-making. Participants first completed a Trust Game (Berg, Dickhaut, \& McCabe, 1995) with another person who was ostensibly taking part in the study in the next cubicle. In the trust game there are two roles, Player A and Player B. Player A is the decision maker. They are allocated 10 tokens and can choose whether to send any number of these tokens to Player B. Any tokens sent to Player B are tripled by the experimenter and Player B can then decide whether to return any number of tokens to Player A. The best joint outcome is obtained if Player A sends a large proportion of their endowment to Player B so the overall number available to two parties increases, and Player B then splits the proceeds equally. Participants were told that each token corresponds to one entry into a lottery for two chances to win $£ 25$ - the more tokens they end with, the more chance of winning the money.

All participants were told that they had been assigned to the role of Player A. Player B was identified by the name 'Chang Wei' signalling their membership in the outgroup (for similar procedure see De Dreu, Greer, Van Kleef, Shalvi, \& Handgraaf, 2011). The participants made their investment decision and the behaviour of Player B was preprogrammed by the experimenter forming the manipulation of intergroup contact. In the negative contact condition, participants were told that Chang Wei had chosen to return 0 tokens - constituting a non-cooperative response. In the neutral contact condition no choice feedback was provided - participants were asked to complete the remaining questionnaires while they waited for Chang Wei to make their decision.

Following the manipulation, participants completed the dependent measures. The dependent measures assessed attitudes towards the outgroup as a whole and a cover story was provided that concerned a partnership the University has formed with an international education agency which had led to an increase in the number of applications from Chinese 
people. Outgroup evaluation was measured with a feeling thermometer scale (Haddock, Zanna, \& Esses, 1993).Participants were asked to indicate how warm (favorable), or cold (unfavorable) they felt towards Chinese people, in general, on a scale from $0^{\circ}$ to $100^{\circ}$. Intentions to engage in future contact with the outgroup were measured with 4 items adapted from Asbrock, Gutenbrunner and Wagner (2013) including "If the opportunity arises, I would probably start a conversation with a Chinese person" and "In the future, I will deliberately approach Chinese people to get in touch" (from $1=$ don't agree at all, to $7=$ completely agree, $\alpha=.81$ ). A number of filler items assessing general political attitudes were also included to help mask our hypotheses. Two participants were chosen at random to receive the lottery payment when data collection was complete.

\section{Results and Discussion}

We were not interested in the amount of tokens participants chose to send to Player B per se, but rather the effect of Player B's alleged non-cooperation on attitudes towards the outgroup, and intentions to interact with members of that group again in the future. Two further participants had to be removed from the analysis at this point because they chose to send zero tokens to Player B and so a return of 0 tokens from this person would not constitute a negative encounter.

An independent samples $t$-test confirmed that attitudes towards Chinese people were significantly reduced in the negative contact condition $(M=67.29, \mathrm{SD}=21.33)$ compared to the neutral contact condition $(M=76.31, \mathrm{SD}=16.83), t(77)=2.08, p=.041, d=.47^{3}$. As the number of tokens participants chose to send to Player B influences the extremity of Player B's non-cooperative response, and could also potentially be considered as an indication of existing prejudice towards the outgroup, we also conducted an ANCOVA controlling for the number of tokens sent in the trust game. This analysis revealed that the covariate was not 
significantly related to evaluation of the outgroup $(p=.53)$ but that the effect of condition remained when accounting for this variable, $F(1,76)=4.05, p=.048, \eta_{\mathrm{p}}^{2}=.05$.

A second set of analyses was then performed with future contact intentions as the dependent variable. Results confirmed that intentions to engage with the outgroup in the future were significantly reduced in the negative contact condition $(M=4.68, \mathrm{SD}=1.09)$, compared to the neutral contact condition $(M=5.31, \mathrm{SD}=0.94), t(79)=2.81, p=.006, d=$ .63. Again, when including the number of tokens the participant sent to Player B in the trust game as a covariate, the effect of contact condition remained, $F(1,78)=7.95, p=.006$, $\eta_{\mathrm{p}}{ }^{2}=.09$. There was no significant effect of the covariate on contact intentions, $p=.79$.

The results of Study 2A provide experimental evidence of the ability of a negative intergroup contact encounter to harm individuals' attitudes towards the outgroup, and intentions to engage with members of that group again in the future. A potential alternative explanation for results could be that participants' responses in the negative contact condition were not a result of the negative intergroup encounter per se, but instead reflect a general negative response to having been victim to a trust violation. To address this potential concern we conducted a second study in which we introduced a third condition where participants also received feedback that Player B had returned 0 tokens in the trust game but this person was not identified as an outgroup member. If the effect is specific to negative intergroup contact, we should find outgroup attitudes and future contact intentions are impaired only when the non-cooperative partner belongs to the target outgroup.

\section{Study 2B}

\section{Participants}


Data was collected from a sample of 158 undergraduate participants. As in Study 1, the recruitment aim was 50 participants per cell. The target outgroup was again Chinese people. Data from 9 participants were removed because they identified as South Asian, or mixed ethnicity. The final sample included 123 females and 25 males (one participant did not report their gender), aged between 18-50 years. Participants were randomly assigned to either the negative outgroup contact condition $(n=46)$, negative ingroup contact condition $(n=52)$ or neutral outgroup contact control $(n=51)$.

\section{Methods}

The experiment followed the same procedure as Study 2A except for the inclusion of a third condition where participants were the recipient of the same non-cooperative response in the trust game but from an ingroup member rather than outgroup member. To do this we varied the name of Player B. They were identified by a typical British name - 'Chris' - rather than by a Chinese name. This condition was designed to recreate the same uncooperative encounter, but without the important intergroup component. Outgroup evaluation and intentions to engage in future outgroup contact $(\alpha=.79)$ were measured with the same items as in Study 2A.

\section{Results and Discussion}

Before the analysis the data of two participants who sent zero tokens were removed. Univariate ANCOVAs were conducted to explore the effect on condition on both outgroup evaluation and intentions to engage in future intergroup contact, controlling for the number of tokens sent to Player B in the trust game. Means by condition are shown in Table $3^{4}$. Results revealed no significant effect of the covariate on outgroup evaluation $(p=.537)$. The effect of condition was, however, significant $F(2,133)=3.74, p=.026, \eta_{p}^{2}=.05$. Pairwise comparisons with a bonferroni adjustment revealed that outgroup evaluation was 
significantly lower in the negative outgroup contact condition than in the negative ingroup contact condition $p=.048$, and marginally significantly lower than in the neutral contact condition, $p=.072$. There was no difference in outgroup evaluation between the negative ingroup contact condition and the neutral outgroup contact condition, $p=.999$. An a priori test comparing the negative outgroup contact condition with the combined neutral contact and negative ingroup contact conditions was significant, $t(133),=2.72, p=.007$

\section{[insert Table 3 here]}

A significant effect of condition on future contact intentions was also observed, $F(2$, $145)=3.43, p=.035, \eta_{p}^{2}=.05$. Again, there was no significant effect of the covariate $(p$ $=.586$ ). The pattern of results was the same whereby contact intentions were lower in the negative outgroup contact condition compared to the negative ingroup contact condition, $p$ $=.045$, and the neutral contact control condition, though this latter pairwise comparison did not reach statistical significance, $p=.156$. There was no difference in contact intentions between the negative ingroup contact condition and the neutral outgroup contact condition, $p$ $=.1 .00$ Again, a priori test comparing the negative outgroup contact condition to the combined neutral contact and negative ingroup contact condition was significant, $t(145),=$ $2.56, p=.012$.

Replicating the pattern of results in Study 2A, Study 2B demonstrated that a negative, non-cooperative encounter with an outgroup member increases prejudice towards the outgroup and lowers intentions to engage with members of that group in the future. Importantly, Study $2 \mathrm{~B}$ was able confirm that effects are not simply a result of being the recipient of a non-cooperative return within the economic game, by demonstrating that effects only emerge when the non-cooperative partner belonged to the outgroup category someone named 'Chang Wei' and not someone named 'Chris'. 


\section{Study 3}

In Study 3 we went on to examine how the impact of negative contact may generalize even beyond the contacted outgroup. Previous research has demonstrated that the attitudinal benefits of positive contact with outgroup members can generalize to the outgroup as a whole, and from here, to other secondary outgroups (e.g. Pettigrew, 2009; Tausch et al., 2010). In Study 3 we examined whether a similar process may exist for the generalization of outgroup avoidance. Specifically, if outgroup avoidance generalizes, the impaired contact intentions that result from negative contact with one group should result in impaired contact intentions towards other outgroups. If this is the case, contact intentions towards the encountered group should mediate the relationship between contact and secondary outgroup contact intentions.

As a second way of exploring the generalized consequences of negative intergroup contact we also measured participants' perceptions of contact self-efficacy in Study 3. Selfefficacy refers to an individual's belief in their ability to successfully perform a specific behaviour (Bandura, 1986). Contact self-efficacy specifically refers to a particular set of beliefs about one's ability to interact effectively with outgroup members (Stathi, Crisp, \& Hogg, 2011). As yet, little intergroup contact research has focused on such efficacy beliefs. In the present study we adopted this construct to explore whether negative contact may manifest not only in reduced intentions to engage with specific primary and secondary outgroups in the future, but may also harm individuals' general confidence in cross-group situations. 


\section{Participants}

Data was collected from a sample of 205 undergraduate participants, which included 182 females and 24 males, aged between 18 and 58. Because we measured attitudes towards a number of ethnic minority immigrant groups in Study 3, the study was only available to White British respondents. No exclusions were made. This sample size was sufficient to provide considerable power (.80) for detecting small to medium mediated effects using biascorrected bootstrapped estimates (Fritz \& MacKinnon, 2007).

\section{Methods}

The primary outgroup target in Study 3 was Muslim immigrants. The measures tapped prior contact with this group, and anticipated future approach towards them. Negative intergroup contact $(\alpha=.88)$ and positive intergroup contact $(\alpha=.89)$ with Muslim immigrants was measured with the same items used in Study 1 (Reimer et al., 2017). Attitudes towards the Muslim immigrants were measured with the General Evaluation Scale as used in Study 1 (Wright et al., 1997, $\alpha=.94$ ). Future contact intentions were measured with the same scale as used in Study 2A and 2B (Asbrock et al., 2013, $\alpha=.88$ ).

To examine how the effect of negative contact may generalize beyond the contacted group, we then also measured contact intentions towards a number of other immigrant groups specifically: Eastern European immigrants, Indian immigrants and Black African immigrants. To avoid shared method variance we used alternative measurement items to those used to measure contact intentions towards the primary group (see Tausch et al., 2010). Specifically, participants reported their intentions to engage with each of the secondary groups in the future on a single item, for example "How much do you intend to interact with Eastern European immigrants in the future" (from $1=$ not at all to $7=$ very $m u c h$, Husnu \& Crisp, 2010). Importantly, we also measured and controlled for participants' prior contact with each secondary group (see Tausch et al., 2010). Both positive and negative contact with 
each of the secondary groups was measured with two single items adapted from Barlow et al., (2012), for example: “On average, how frequently do you have positive/good contact with Eastern European immigrants”, “On average, how frequently do you have negative/bad contact with Eastern European immigrants" (from 1 = never to 7 = extremely frequently).

Finally, contact self-efficacy was measured with a scale adapted from Stathi et al., (2011). This measure was conceptualised as another test of the generalization potential of negative contact because it was not restricted to any particular group but instead assessed efficacy beliefs regarding contact with 'immigrants' in general. Participants rated their agreement with six items including "I would be worried that I might not handle myself well in social gatherings with immigrants*", "I would feel confident talking with immigrants", "I would feel I have common topics of conversation with an immigrant" $(1=$ strongly disagree to 7 strongly agree, $\alpha=.80)$.

\section{Results and Discussion}

The correlations amongst all variables are presented in Table 4 with means and standard deviations ${ }^{5}$. A paired samples $t$-test indicated that people reported more positive contact with Muslim immigrants $(M=2.92, S D=0.97)$ than negative contact $(M=1.47, S D$ $=0.69), t(205)=16.94, p<.001, d=1.18$.

\section{[insert Table 4 here]}

A series of regressions were then conducted to examine the unique effect of negative and positive contact with Muslim immigrants on the dependent variables (see Table 5).

Together, negative and positive intergroup contact experience explained a significant amount of variance in outgroup evaluation. As expected, negative contact with Muslim immigrants was associated with lower evaluation of this group $(\beta=-.43, p<.001)$ while positive contact was associated with higher outgroup evaluation $(\beta=.47, p<.001)$. Contact experiences also 
explained a significant amount of variance in future contact intentions. The more negative contact experience individuals had with Muslim immigrants, the lower their intentions to engage with this group again in the future $(\beta=-.24, p<.001)$. Positive contact, meanwhile, was positively associated with future contact intentions $(\beta=-.42, p<.001)$. Negative and positive contact with Muslim immigrants also explained a significant amount of variance in perceptions of contact self-efficacy. As expected, negative contact experience was associated with lower contact self-efficacy $(\beta=-.30, p<.001)$, while positive contact was associated with higher contact self-efficacy $(\beta=.37, p<.001)$.

\section{[insert Table 5 here]}

The generalization of contact effects to secondary outgroups was then investigated by examining the indirect path from negative and positive contact with Muslim immigrants to contact intentions towards secondary outgroups through contact intentions towards the primary outgroup. The examination of the indirect path constitutes the most appropriate test of the secondary transfer effect because it specifically tests the generalization process in which negative contact promotes avoidance of the contacted group, which then spreads to other, non-contacted groups (for similar procedure see Harwood et al., 2011). The analysis was conducted using bootstrapped tests of the indirect path (based on 5,000 bootstrapped resamples), with effects calculated using Hayes (2013) PROCESS macro (Model 4). Analyses were conducted separately for negative contact and positive contact. Within each mediational model, negative contact [positive contact] with the primary outgroup represented the independent variable, contact intentions towards the primary outgroup was the mediator, and contact intentions towards the secondary outgroups was the dependent variable. Negative contact with the secondary outgroup [positive contact with the secondary outgroup] was 
included as a covariate. Separate models were tested for each of the three secondary groups (6 models in total).

Total, direct and indirect effects are shown in Table 6. Results showed that, when controlling for secondary outgroup contact, there was no significant total or direct effect of negative contact with Muslim immigrants on contact intentions towards any of the secondary groups. Instead, significant indirect effects emerged in every case. Negative contact was indirectly associated with lower contact intentions towards Eastern European immigrants, Indian immigrants and Black African immigrants via reduced contact intentions towards the primary group. Meanwhile positive contact was indirectly associated with higher contact intentions towards each secondary outgroup via increased contact intentions towards the primary group.

\section{[insert Table 6 here]}

A further series of models were then tested using an adaptation to the PROCESS macro which allows for multiple predictor variables (Hayes, 2013). In doing so, we are able to confirm the whether the indirect effects of negative contact persist when controlling for positive contact, and vice versa. In each model, negative and positive contact with Muslim immigrants were entered simultaneously as independent variables, contact intentions towards Muslim immigrants was the mediator, and contact intentions towards the secondary outgroup was the dependent variable. Positive and negative contact with the secondary outgroup was included as covariates. Again, separate analyses were performed for each of the three secondary groups ( 3 models in total). As can be seen in Table 6 , the same pattern of indirect effects replicate with this method of analysis.

In Study 3 we report the first evidence of an 'avoidance generalization effect' whereby negative intergroup contact is associated with lower future contact intentions not 
only towards the contacted outgroup, but also, indirectly, with contact intentions towards other, non-contacted groups. We did not find evidence of an overall association between negative contact with Muslim immigrant and avoidance of other immigrant groups after controlling for contact with the secondary group. Rather, our results point to the emergence of an indirect effect, such that contact with Muslim immigrants is associated with lower intentions to engage with secondary outgroups via reductions in contact intentions towards the primary group.

Evidence was also found for an association between negative contact and lower perceptions of contact self-efficacy. This measure was conceptualised as another test of the generalized effects of the intergroup contact because it was not restricted to any particular group, but instead assessed efficacy beliefs regarding interactions with immigrants in general. While positive contact with Muslim immigrants was associated with increased confidence in one's ability to interact effectively with immigrants, in general, negative contact was associated with lower perceived self-efficacy. Together, findings highlight the dangers of negative intergroup contact and demonstrate the extent to which the effect of negative intergroup contact extend beyond the encountered group to secondary outgroups as well as to more general beliefs about one's preparedness for intercultural contact.

\section{General Discussion}

Relative to positive intergroup contact, the influence of negative intergroup contact has received considerably less scientific attention. Recent research has taken important first steps to demonstrate the prejudice-enhancing potential of negative contact. The present research now aimed to provide to a broader understanding of the consequences of negative contact focusing in particular on what McKeown and Dixon (2017) referred to as informal practices of social segregation. Hewstone (2015) recently referred to segregation as the 
“enemy of intergroup contact" (p. 432). In our view, it is not simply the case that segregation impedes the opportunity for intergroup contact, but that the quality of individuals' prior contact experiences determine their willingness to take advantage of opportunities for interaction across group lines. Across three studies we demonstrate that negative intergroup contact is associated not just with increased prejudice, with reduced intentions to engage in further outgroup outreach.

Study 1 was a cross-sectional study conducted in the aftermath of Britain's decision to leave the EU by referendum in 2016. While negative contact is the primary focus of this investigation, we measured both positive and negative contact experience with EU immigrants as simultaneous predictor variables. Results suggest that while positive contact can act as a reward system and fuel interest in further contact with the outgroup, negative contact with EU immigrants is associated with outgroup avoidance. Effects emerged across two different operationalizations of outgroup avoidance - active avoidance and issue avoidance. Negative contact was also uniquely associated with the denial of discrimination experienced by this group. Study 2 provided a conceptual replication on the impact of negative contacts on outgroup avoidance with an experimental design. Studying negative intergroup contact in the laboratory sacrifices some external validity, but allows more confidence in drawing causal conclusions. Negative intergroup contact was manipulated within the context of an economic game which participants ostensibly completed with a Chinese partner. Compared to a neutral contact condition, a negative intergroup encounter where individuals discovered that their trust has been violated by an outgroup member resulted in increased prejudice and lower intentions to engage with this outgroup in the future. A follow-up study ruled out a possible alternative explanation for results by confirming that these same effects did not emerge following the same non-cooperative encounter with an ingroup member. 
Study 3 went on to demonstrate that the influence of negative intergroup contact is not limited to the outgroup with whom the contact occurred, but can also compromise engagement with other minority groups. Contact was Muslim immigrants was found to be indirectly associated with reduced contact intentions towards secondary outgroups, via reductions in contact intentions towards the primary outgroup. The fact that we did not find a direct association between primary outgroup contact and secondary outgroup intentions (after controlling for secondary outgroup contact) does not undermine the validity of our results. Indeed, this pattern of indirect effects in the absence of direct effects is not uncommon in the literature on the secondary transfer effects of intergroup contact (e.g. Brylka et al., 2016; Drury, Abrams, Swift, Lamont, Gerocova, 2017; Harwood et al., 2011; Vezzali \& Giovanni, 2012). In this study we employed a new outcome variable, exploring the generalization of avoidance rather than attitudes. The generalization of avoidance occurred as statistically significant indirect effects of negative contact with the primary group on contact intentions towards secondary outgroup, through contact intentions towards the primary group. We refer to this process as an 'avoidance generalization effect'. Finding strategies that can break this negative spiral will represent an important challenge for future intergroup contact research.

We also observed an association between both types of contact andperceptions of contact self-efficacy. Little previous contact research has explored this construct, yet it is recognized as an important regulator of human behaviour (Bandura, 1986). We would encourage future research to explore contact self-efficacy as a further variable dependent on previous contact experience. While we report encouraging evidence that positive intergroup contact is associated with higher levels of confidence in one's ability to interact effectively in future envisaged intergroup encounters, negative contact is negatively associated with efficacy beliefs. Moreover, because contact self-efficacy was measured at a higher level of categorization (tapping efficacy regarding contact with immigrants, in general) findings 
suggest that reductions in confidence the result from negative contact are not restricted to one particular outgroup.

In line with previous results we found that negative contact occurred less frequently than positive contact (e.g. Barlow et al., 2012; Dhont \& Van Hiel, 2009; Graf et al., 2014). Previous studies also often find negative contact to be a stronger predictor of prejudice than positive contact. While the aim of our paper was to broaden the understanding of the breath of negative contact effects rather than to test for positive-negative contact asymmetry effects, this comparison is possible in Study 1 and $3^{6}$. In terms of outgroup attitudes, positive contact was actually a stronger predictor than negative contact in both cases, indicating a contact asymmetry in favour of positive contact. This finding is consistent with previous observations of the strength of positive contact in predicting affective outcomes (Aberson, 2015; Hayward et al., 2017). In terms of outgroup avoidance there was no consistent pattern in the relative magnitude of positive and negative contact effects. In Study 1, negative contact was the stronger predictor while in Study 3, positive contact was the stronger predictor. This finding may relate to the different measurement instruments used in these two studies. In Study 1, the measures used assessed participants avoidance of the outgroup (both in terms of face-to-face interaction, and the avoidance of sensitive intergroup topics), whereas the contact intentions items used throughout the rest of the investigation assessed individuals' intention to approach outgroup members. This finding warrants further attention and suggests that negative contact may potentially represent a stronger predictor of avoidance tendencies, while positive contact is a stronger predictor of approach tendencies. More generally, findings add to growing appreciation of the caveats and nuances of the positive-negative contact asymmetry effects (see Pettigrew \& Hewstone, 2017). 
Interestingly, we found negative contact to be uniquely associated with a measure of denial of discrimination included in Study 1. This is an important outcome for consideration in light of a recent arguments that for contact to promote social change, it must not only improve majority group members' attitudes towards disadvantaged groups, but also increase support for policies aimed at redressing inequality (e.g. Dixon et al., 2012, 2010; McKeown \& Dixon, 2017). In the present case, we did not find evidence that positive intergroup contact increased recognition of intergroup discrimination. Perhaps more troubling, is the finding that negative contact was associated with the denial of the discrimination. This finding is likely to have implications for individuals' willingness collective action on behalf of the disadvantaged group, as well as their acceptance of structural change that arises from the disadvantaged group's own collective action (although see Reimer et al., 2017 who did not find perceived discrimination to explain the relationship between negative contact and collective action tendencies).

\section{Limitations}

There are some limitations to the present research that should be acknowledged. First, the secondary outgroups under consideration in Study 3 were all high in similarity to the focal outgroup (Muslim immigrants) in that they represented three further immigrant groups (Eastern European immigrants, Black African immigrants and Indian immigrants). It will be important for future research to explore whether effects extend to more dissimilar groups, or groups stigmatised on different underlying dimensions (e.g. Fiske, Cuddy, Glick, \& Xu, 2002). It is likely that a stimulus generalization gradient exists whereby transfer effects are larger for more similar groups and smaller for less similar groups (Harwood et al., 2011). Moreover, evidence of the generalized consequences of negative intergroup contact relies on cross-sectional data and so it is not possible to make firm conclusions regarding causality. 
Previous research has provided evidence of the attitudinal secondary transfer effects with both longitudinal (e.g. Eller \& Abrams, 2004; Pettigrew, 2009; Tausch et al., 2010; Van Laar, Levin, Sinclair, \& Sidanius, 2005) and experimental data (e.g. Galinsky \& Moskowitz, 2000; Harwood et al., 2011), and we interpreted our findings accordingly. Nevertheless, we invite further research examining the generalization of outgroup avoidance using longitudinal or experimental designs.

We do provide experimental evidence of the influence on negative contact on contact intentions towards the primary outgroup within Study 2A and 2B. Some effects did fall short of statistical significance in these experiments. We do not believe this poses a serious problem as we replicate the same basic pattern of results across four studies. Nevertheless, future investigations may benefit from employing more powerful manipulations of negative contact. We chose to manipulate negative contact within the context of an economic game because it allowed us to model a situation of interdependence between individuals where the non-cooperation of an outgroup member has real implications for the provision of valued resources. The particular economic game we chose involved a 'one-shot' uncooperative signal from an outgroup member, and did not include the opportunity any further interaction with that person. Future studies may consider using iterated games where participants make several cooperative or competitive choices over repeated trials, or tasks that involve face-toface contact manipulations such as Paolini's and colleagues manipulation of outgroup confederates' non-verbal behaviour (Paolini, Harwood, \& Rubin, 2010).

Finally, while we examined the impact of negative intergroup contact across three different intergroup contexts, participants were always drawn from a sample of British University students. As is common with such samples, there was also a gender skew in our sample and a small number of male respondents. It will be important for future research to 
replicate these effects within more representative samples. Replication sought also be sought in more conflictual intergroup context. In all studies reported in the present investigation evaluation of the outgroup was fairly positive, with negative contact serving to reduce this positivity in the direction of the midpoint of the scale. This is likely driven to some extent by social desirability and self-presentational concerns, however, it will be also important to explore what this might mean for the flow-on behavioural consequences of negative contact and whether it translates to a reduction in positive intergroup behaviours (e.g. helping behaviours) versus an increase in harmful intergroup behaviours (e.g. verbal or physical confrontations).

\section{Conclusions}

It is important to note that evidence of the influence of negative intergroup contact does not dispute the merits of positive intergroup contact, but rather invites a full understanding of intergroup contact effects. Here, we provide evidence of the impact on negative intergroup contact on outcomes beyond standard indices of prejudice - principally on measures of outgroup avoidance, but also on measures of contact self-efficacy and the denial of intergroup discrimination. These studies substantiate the impact of and importance of negative contact research. It will be important for future research to continue to investigate this lesser understood type of contact in order to understand the full range of its attitudinal and behavioural consequences. 


\section{References}

Aberson, C. L. (2015). Positive intergroup contact, negative intergroup contact, and threat as predictors of cognitive and affective dimensions of prejudice. Group Processes \& Intergroup Relations, 18(6), 743-760. doi:10.1177/1368430214556699

Al Ramiah, A., \& Hewstone, M. (2013). Intergroup contact as a tool for reducing, resolving, and preventing intergroup conflict: Evidence, limitations, and potential. American Psychologist, 68(7), 527-542. doi:10.1037/a0032603

Alexander, L., \& Tredoux, C. (2010). The spaces between us: A spatial analysis of informal segregation at a South African university. Journal of Social Issues, 66(2), 367-386. doi:10.1111/j.1540-4560.2010.01650.x

Allport, G. W. (1954). The Nature of Prejudice. London: Addison-Wesley.

Aron, A., Melinat, E., Aron, E. N., Vallone, R., \& Bator, R. (1997). The experimental generation of interpersonal closeness: A procedure and some preliminary findings. Personality and Social Psychology Bulletin, 23, 363-377. doi: $10.1177 / 0146167297234003$

Asbrock, F., Gutenbrunner, L., \& Wagner, U. (2013). Unwilling, but not unaffectedImagined contact effects for authoritarians and social dominators. European Journal of Social Psychology, 43(5), 404-412. doi:10.1002/ejsp.1956

Bandura, A. (1986). Social foundations of though and action: A social cognitive theory. Englewood Cliffs, NJ: Prentice-Hill, Inc.

Barlow, F. K., Paolini, S., Pedersen, A., Hornsey, M. J., Radke, H. R., Harwood, J., ... \& Sibley, C. G. (2012). The contact caveat negative contact predicts increased prejudice more than positive contact predicts reduced prejudice. Personality and Social Psychology Bulletin, 38(12), 1629-1643. doi:10.1177/0146167212457953 
BBC News (2017, February). 'Record hate crimes' after EU referendum. Retrieved from: http://www.bbc.co.uk/news/uk-38976087

Bekhuis, H., Ruiter, S., \& Coenders, M. (2013). Xenophobia among youngsters: The effect of inter-ethnic contact. European Sociological Review, 29(2), 229-242. doi:10.1093/esr/jcr057

Berg, J., Dickhaut, J., \& McCabe, K. (1995). Trust, reciprocity, and social history. Games and Economic Behavior, 10(1), 122-142. doi:10.1006/game.1995.1027

Braddock, J. H. (1980). The perpetuation of segregation across levels of education: A behavioral assessment of the contact-hypothesis. Sociology of Education, 178-186. doi: $10.2307 / 2112412$

Braddock, J. H., \& McPartland, J. M. (1989). Social-psychological processes that perpetuate racial segregation: The relationship between school and employment desegregation. Journal of Black Studies, 19(3), 267-289. doi:10.1177/002193478901900301

Brown, R., \& Hewstone, M. (2005). An integrative theory of intergroup contact. Advances in Experimental Social Psychology, 37, 255-343. doi:10.1016/S0065-2601(05)37005-5

Brylka, A., Jasinskaja-Lahti, I., \& Mähönen, T. A. (2016). The majority influence on interminority attitudes: The secondary transfer effect of positive and negative contact. International Journal of Intercultural Relations, 50, 76-88. doi:10.1016/j.ijintrel.2015.12.007

Butz, D.A., \& Plant, E.A. (2006). Perceiving outgroup members as unresponsive: Implications for approach-related emotions, intentions, and behavior. Journal of Personality and Social Psychology, 91, 1066-1079. doi: 10.1037/00223514.91.6.1066

De Dreu, C. K., Greer, L. L., Van Kleef, G. A., Shalvi, S., \& Handgraaf, M. J. (2011). Oxytocin promotes human ethnocentrism. Proceedings of the National Academy of 
Sciences in the United States of America, 108(4), 1262-1266. doi:

\subsection{3/pnas.1015316108}

Dhont, K., \& Van Hiel, A. (2009). We must not be enemies: Interracial contact and the reduction of prejudice among authoritarians. Personality and Individual Differences, 46(2), 172-177. doi:10.1016/j.paid.2008.09.022

Dixon, J., \& Durrheim, K. (2003). Contact and the ecology of racial division: Some varieties of informal segregation. British Journal of Social Psychology, 42(1), 1-23. doi:10.1348/014466603763276090

Dixon, J., Durrheim, K., Tredoux, C. G., Tropp, L. R., Clack, B., Eaton, L., \& Quayle, M. (2010). Challenging the stubborn core of opposition to equality: Racial contact and policy attitudes. Political Psychology, 31(6), 831-855. doi: 10.1111/j.14679221.2010.00792.x

Dixon, J., Levine, M., Reicher, S., \& Durrheim, K. (2012). Beyond prejudice: Are negative evaluations the problem and is getting us to like one another more the solution? Behavioral and Brain Sciences, 35(06), 411-425. doi: 10.1017/S0140525X11002214

Drury, L., Abrams, D., Swift, H., Lamont, R.A., Gerocova, K. (2017). Can caring create prejudice? An investigation of positive and negative intergenerational contact in care settings and the generalization of blatant and subtle age prejudice to other older people. Journal of Community \& Applied Social Psychology, 27; 65-82. doi: 10.1002/casp.2294

Eller, A., \& Abrams, D. (2004). Come together: longitudinal comparisons of Pettigrew's reformulated intergroup contact model and the common ingroup identity model in Anglo-French and Mexican-American contexts. European Journal of Social Psychology, 34(3), 229-256. doi:10.1002/ejsp.194 
Faul, F., Erdfelder, E., Buchner, A., \& Lang, A.-G. (2009). Statistical power analyses using G*Power 3.1: Tests for correlation and regression analyses. Behavior Research Methods, 41, 1149-116. doi: 10.3758/BRM.41.4.1149.

Fiske, S. T., Cuddy, A. J., Glick, P., \& Xu, J. (2002). A model of (often mixed) stereotype content: competence and warmth respectively follow from perceived status and competition. Journal of Personality and Social Psychology, 82(6), 878-902. doi:10.1037/0022-3514.82.6.878

Galinsky, A. D., \& Moskowitz, G. B. (2000). Perspective-taking: decreasing stereotype expression, stereotype accessibility, and in-group favoritism. Journal of Personality and Social Psychology, 78(4), 708-724. doi:10.1037/0022-3514.78.4.708

Graf, S., \& Paolini, S. (2017). Investigating Positive and negative intergroup contact: Rectifying a long standing positivity bias in the literature. In L. Vezzali \&. S. Stathi (Eds.), Intergroup contact theory: Recent developments and future directions (pp. $92-$ 113). London: Routledge

Graf, S., Paolini, S., \& Rubin, M. (2014). Negative intergroup contact is more influential, but positive intergroup contact is more common: Assessing contact prominence and contact prevalence in five Central European countries. European Journal of Social Psychology, 44(6), 536-547. doi:10.1002/ejsp.2052

Haddock, G., Zanna, M. P., \& Esses, V. M. (1993). Assessing the structure of prejudicial attitudes: The case of attitudes toward homosexuals. Journal of Personality and Social Psychology, 65(6), 1105. doi:10.1037/0022-3514.65.6.1105

Harwood, J., Paolini, S., Joyce, N., Rubin, M., \& Arroyo, A. (2011). Secondary transfer effects from imagined contact: Group similarity affects the generalization gradient. British Journal of Social Psychology, 50(1), 180-189. doi:10.1348/014466610X524263 
Hayes, A. F. (2013). Introduction to mediation, moderation, and conditional process analysis: A regression-based approach. New York: Guilford Press.

Hayward, L. E., Tropp, L. R., Hornsey, M. J., \& Barlow, F. K. (2017). Toward a comprehensive understanding of intergroup contact: Descriptions and mediators of positive and negative contact among majority and minority groups. Personality and Social Psychology Bulletin, 43(3), 347-364. doi:10.1177/0146167216685291

Hewstone, M. (2015). Consequences of diversity for social cohesion and prejudice: The missing dimension of intergroup contact. Journal of Social Issues, 71(2), 417-438. doi:10.1111/josi. 12120

Lolliot, S., Schmid, K., Hewstone, M., Al Ramiah, A., Tausch, N., \& Swart, H. (2013). Generalized effects of intergroup contact. In G. Hodson \& M. Hewstone (Eds.), Advances in intergroup contact (pp.81-112). London: Psychology Press

Husnu, S., \& Crisp, R. J. (2010). Elaboration enhances the imagined contact effect. Journal of Experimental Social Psychology, 46(6), 943-950. doi:10.1016/j.jesp.2010.05.014

McKeown, S., \& Dixon, J. (2017). The "contact hypothesis": Critical reflections and future directions. Social and Personality Psychology Compass, 11(1), 1-13, doi:10.1111/spc3.12295

Meleady, R. Seger, C.R. \& Vermue, M. (2017). Examining the role of positive and negative intergroup contact and anti-immigrant prejudice in Brexit. British Journal of Social Psychology. Advance online publication. doi: 10.1111/bjso.12203

Page-Gould E, Mendoza-Denton R, Tropp LR (2008). With a little help from my cross-group friend: Reducing anxiety in intergroup contexts through cross-group friendship. Journal of Personality and Social Psychology, 95, 1080-1094. doi: 10.1037/00223514.95.5.1080. 
Paolini, S., Harwood, J., \& Rubin, M. (2010). Negative intergroup contact makes group memberships salient: explaining why intergroup conflict endures. Personality and Social Psychology Bulletin, 36(12), 1723-1738. doi:10.1177/0146167210388667

Pettigrew, T. F. (2008). Future directions for intergroup contact theory and research.

International Journal of Intercultural Relations, 32(3), 187-199. doi:10.1016/j.ijintrel.2007.12.002

Pettigrew, T. F. (2009). Secondary transfer effect of contact: Do intergroup contact effects spread to noncontacted outgroups? Social Psychology, 40(2), 55-65. doi:10.1027/1864-9335.40.2.55

Pettigrew, T. F., \& Hewstone, M. (2017). The single factor fallacy: Implications of missing critical variables from an analysis of intergroup contact theory. Social Issues and Policy Review, 11(1), 8-37. doi:10.1111/sipr.12026

Pettigrew, T. F., \& Tropp, L. R. (2006). A meta-analytic test of intergroup contact theory. Journal of Personality and Social Psychology, 90(5), 751-783. doi:10.1037/00223514.90.5.751

Pettigrew, T. F., \& Tropp, L. R. (2011). When groups meet: The dynamics of intergroup contact. New York: Psychology Press.

Plant, E.A., \& Devine, P.G. (2003). The antecedents and implications of interracial anxiety. Personality and Social Psychology Bulletin, 29, 790-801. doi: $10.1177 / 0146167203029006011$

Reimer, N. K., Becker, J. C., Benz, A., Christ, O., Dhont, K., Klocke, U., ... \& Hewstone, M. (2017). Intergroup contact and social change: Implications of negative and positive contact for collective action in advantaged and disadvantaged groups. Personality and Social Psychology Bulletin, 43(1), 121-136. doi:10.1177/0146167216676478 
Stark, T. H., Flache, A., \& Veenstra, R. (2013). Generalization of positive and negative attitudes toward individuals to outgroup attitudes. Personality and Social Psychology Bulletin, 39(5), 608-622. doi:10.1177/0146167213480890

Stathi, S., Crisp, R. J., \& Hogg, M. A. (2011). Imagining intergroup contact enables memberto-group generalization. Group Dynamics: Theory, Research, and Practice, 15(3), 275-284. doi:10.1037/a0023752

Tausch, N., Hewstone, M., Kenworthy, J. B., Psaltis, C., Schmid, K., Popan, J. R., ... \& Hughes, J. (2010). Secondary transfer effects of intergroup contact: Alternative accounts and underlying processes. Journal of Personality and Social Psychology, 99(2), 282. doi:10.1037/a0018553

Techakesari, P., Barlow, F. K., Hornsey, M. J., Sung, B., Thai, M., \& Chak, J. L. (2015). An investigation of positive and negative contact as predictors of intergroup attitudes in the United States, Hong Kong, and Thailand. Journal of Cross-Cultural Psychology, 46(3), 454-468. doi:10.1177/0022022115570313

Todd, A. R., Bodenhausen, G. V., \& Galinsky, A. D. (2012). Perspective taking combats the denial of intergroup discrimination. Journal of Experimental Social Psychology, 48(3), 738-745. doi:10.1016/j.jesp.2011.12.011

Tredoux, C. G., \& Dixon, J. A. (2009). Mapping the multiple contexts of racial isolation: The case of Long Street, Cape Town. Urban Studies, 46(4), 761-777. doi:10.1177/0042098009102128

Tredoux, C., Dixon, J., Underwood, S., Nunez, D., \& Finchilescu, G. (2005). Preserving spatial and temporal dimensions in observational data of segregation. South African Journal of Psychology, 35(3), 412-432. doi:10.1177/008124630503500302 
Tropp, L. R. (2003). The psychological impact of prejudice: Implications for intergroup contact. Group Processes and Intergroup Relations, 6, 131-149. doi: $10.1177 / 1368430203006002001$

Van Laar, C., Levin, S., Sinclair, S., \& Sidanius, J. (2005). The effect of university roommate contact on ethnic attitudes and behavior. Journal of Experimental Social Psychology, 41(4), 329-345. doi:10.1016/j.jesp.2004.08.002

Vezzali, L. \& Giovannini, D. (2012). Secondary transfer effects of intergroup contact: The role of intergroup attitudes, intergroup anxiety and perspective taking. Journal of Community and Applied Social Psychology, 22, 125-144. doi: 10.1002/casp.1103

Visintin, E. P., Green, E. G., Pereira, A., \& Miteva, P. (2017). How positive and negative contact relate to attitudes towards Roma: Comparing majority and high-status minority perspectives. Journal of Community \& Applied Social Psychology, 27(3), 240-252. doi:10.1002/casp.2309

Visintin, E. P., Voci, A., Pagotto, L., \& Hewstone, M. (2016). Direct, extended, and massmediated contact with immigrants in Italy: their associations with emotions, prejudice, and humanity perceptions. Journal of Applied Social Psychology. doi:10.1111/jasp.12423

Wright, S. C., Aron, A., McLaughlin-Volpe, T., \& Ropp, S. A. (1997). The extended contact effect: Knowledge of cross-group friendships and prejudice. Journal of Personality and Social Psychology, 73(1), 73-90. doi:10.1037/0022-3514.73.1.73 


\section{Notes}

${ }^{1}$ Data are available on request from the corresponding author.

${ }^{2}$ An exploratory factor analyses were conducted to rule out the possibility that there is conceptual overlap between measures of outgroup evaluation and outgroup avoidance. We entered the three sets of items into a factor analysis with varimax rotation, retaining eigenvalues greater than 1 . The analysis revealed three distinct factors; each set of items loading strongly on their respective factors (loadings were greater than .72 for outgroup evaluation, .78 for issue avoidance and .62 for active avoidance).

${ }^{3}$ The $d f$ for the analysis of outgroup evaluation is slightly lower than that of future contact intentions due to some missing data on the feeling thermometer scale.

${ }^{4}$ The bivariate correlation between outgroup evaluation and contact intentions in Study $2 \mathrm{~A}$ was .328, and .275 in Study 2B.

${ }^{5}$ As per Study 1, the items from the measure of outgroup evaluation and future contact intentions were entered into a factor analysis which revealed two distinctive factors (all other eigenvalues $<1$ ) corresponding to outgroup evaluation and contact intentions (loadings were greater than .76 for outgroup evaluation, and greater than .70 for contact intentions).

${ }^{6}$ To test for positive-negative contact asymmetry effects we followed the analytic procedure of Barlow et al., (2012). The absolute values of positive and negative contact coefficients from the regression analyses and the correlation between predictors were entered into a $t$-test that examined the difference between two related coefficients, using the equation $t=\left(b_{1}-b_{2}\right)$ / $\mathrm{SE}_{(\mathrm{b} 1-\mathrm{b} 2) .}$ This tests revealed that the slopes differed significantly from one another, with positive contact being a stronger predictor of outgroup evaluation than negative contact in both Study $1, t(135)=8.76, p<.001$, and Study $3, t(202)=12.48, p<.001$. In terms of 
outgroup avoidance, negative contact was found to be a stronger predictor of active avoidance in Study $1, t(135)=5.41, p<.001$, but positive contact being a stronger predictor of future contact intentions in Study 3, $t(202)=7.90, p<.001$. 
Table 1

Correlations and descriptive statistics for all variables in Study 1.

\begin{tabular}{|c|c|c|c|c|c|c|c|}
\hline & $\begin{array}{c}\mathrm{M} \\
(S D)\end{array}$ & 1 & 2 & 3 & 4 & 5 & 6 \\
\hline (1) Negative contact & $\begin{array}{c}1.67 \\
(0.89)\end{array}$ & - & & & & & \\
\hline (2) Positive contact & $\begin{array}{c}3.41 \\
(0.89)\end{array}$ & $-.32 * *$ & - & & & & \\
\hline $\begin{array}{l}\text { (3) Outgroup } \\
\text { evaluation }\end{array}$ & $\begin{array}{c}5.68 \\
(1.01)\end{array}$ & $-.45 * *$ & $.53 * *$ & - & & & \\
\hline (4) Active avoidance & $\begin{array}{c}2.11 \\
(0.98)\end{array}$ & $.37 * *$ & $-.32 * *$ & $-.60 * *$ & - & & \\
\hline (5) Issue avoidance & $\begin{array}{c}2.99 \\
(1.27)\end{array}$ & $.35^{* *}$ & $-.49 * *$ & $-.54 * *$ & $.43 * *$ & - & \\
\hline $\begin{array}{l}\text { (6) Denial of } \\
\text { discrimination }\end{array}$ & $\begin{array}{c}2.85 \\
(0.70)\end{array}$ & $.20 *$ & -.07 & $-.20 *$ & $.23^{*}$ & .14 & - \\
\hline
\end{tabular}

$* p<.05, * * p<.001$, 
Table 2

Positive and negative contact as predictors of outgroup evaluation, issue avoidance, active avoidance and denial of discrimination (Study 1).

\begin{tabular}{|c|c|c|c|c|c|c|c|c|c|c|c|c|}
\hline & \multicolumn{3}{|c|}{ Outgroup evaluation } & \multicolumn{3}{|c|}{ Active avoidance } & \multicolumn{3}{|c|}{ Issue avoidance } & \multicolumn{3}{|c|}{ Denial of discrimination } \\
\hline & $b(\mathrm{SE})$ & $\beta$ & $s r^{2}$ & $b(\mathrm{SE})$ & $\beta$ & $s r^{2}$ & $b(\mathrm{SE})$ & $\beta$ & $s r^{2}$ & $b(\mathrm{SE})$ & $\beta$ & $s r^{2}$ \\
\hline \multicolumn{13}{|l|}{ Baseline model } \\
\hline Intercept & 4.71 & & & 2.30 & & & 4.40 & & & 2.57 & & \\
\hline Negative contact & $-.41(.01)^{* *}$ & -.31 & .09 & $.39(.11)^{* *}$ & .30 & .08 & $.37(.12)^{*}$ & .22 & .04 & $.18(.08)^{*}$ & .20 & .03 \\
\hline Positive contact & $.49(.08)^{* *}$ & .43 & .17 & $-.24(.09)^{*}$ & -.22 & .04 & $-.59(.11)^{* *}$ & -.42 & .16 & $-.01(.07)$ & -.01 & $<.01$ \\
\hline$F$ & \multicolumn{3}{|c|}{$39.14 * *$} & \multicolumn{3}{|c|}{$14.96 * *$} & \multicolumn{3}{|c|}{$26.32 * *$} & \multicolumn{3}{|c|}{2.83} \\
\hline$R^{2}$ & \multicolumn{3}{|c|}{.37} & \multicolumn{3}{|c|}{.18} & \multicolumn{3}{|c|}{.28} & \multicolumn{3}{|c|}{.04} \\
\hline
\end{tabular}

$* p<.05, * * p<.001$ 
Negative contact and outgroup avoidance 43

Table 3

Mean outgroup evaluation and future contact intentions by condition in Study 2B.

\begin{tabular}{lcccc}
\hline & \multicolumn{2}{c}{ Outgroup evaluation } & \multicolumn{2}{c}{ Contact intentions } \\
\cline { 2 - 5 } & $M$ & SD & $M$ & SD \\
\cline { 2 - 5 } Negative outgroup contact & 63.74 & 20.76 & 4.78 & 1.02 \\
Negative ingroup contact & 74.10 & 17.79 & 5.27 & 1.00 \\
Neutral outgroup contact & 73.37 & 20.36 & 5.17 & 0.93 \\
\hline
\end{tabular}


Table 4

Correlations and descriptive statistics for all variables in Study 3.

\begin{tabular}{|c|c|c|c|c|c|c|c|c|c|}
\hline & $\begin{array}{c}\mathrm{M} \\
(S D)\end{array}$ & 1 & 2 & 3 & 4 & 5 & 6 & 7 & 8 \\
\hline (1) Negative contact & $\begin{array}{c}1.47 \\
(0.69)\end{array}$ & - & & & & & & & \\
\hline (2) Positive contact & $\begin{array}{c}2.92 \\
(0.97)\end{array}$ & -.08 & - & & & & & & \\
\hline (3) Outgroup evaluation & $\begin{array}{c}5.26 \\
(1.16)\end{array}$ & $-.47 * *$ & $.50 * *$ & - & & & & & \\
\hline (4) Contact intentions & $\begin{array}{c}4.72 \\
(1.28)\end{array}$ & $-.27 * *$ & $.43 * *$ & $.69 * *$ & - & & & & \\
\hline (5) Contact self-efficacy & $\begin{array}{c}6.02 \\
(1.06)\end{array}$ & $-.33 * *$ & $.39 * *$ & $.55 * *$ & $.61 * *$ & - & & & \\
\hline $\begin{array}{l}\text { (6) Secondary outgroup } \\
\text { intentions - Eastern } \\
\text { European immigrants }\end{array}$ & $\begin{array}{c}4.85 \\
(1.40)\end{array}$ & $-.21^{*}$ & $.27 * *$ & $.45^{* *}$ & $.58 * *$ & $.45^{* *}$ & - & & \\
\hline $\begin{array}{l}\text { (7) Secondary outgroup } \\
\text { intentions - Indian } \\
\text { immigrants }\end{array}$ & $\begin{array}{c}4.78 \\
(1.38)\end{array}$ & $-.15^{*}$ & $.41 * *$ & $.55 * *$ & $.67 * *$ & $.48 * *$ & $.68 * *$ & - & \\
\hline $\begin{array}{l}\text { (8) Secondary outgroup } \\
\text { intentions - Black } \\
\text { African immigrants }\end{array}$ & $\begin{array}{c}4.97 \\
(1.30)\end{array}$ & $-.14^{*}$ & $.36 * *$ & $.48 * *$ & $.53 * *$ & $.50 * *$ & $.72 * *$ & $.76 * *$ & - \\
\hline
\end{tabular}

$* p<.05, * * p<.001$ 
Table 5

Positive and negative contact with Muslim immigrants as predictors of outgroup evaluation and contact intentions towards this group, as well as general contact self-efficacy (Study 3).

\begin{tabular}{|c|c|c|c|c|c|c|c|c|c|}
\hline & \multicolumn{3}{|c|}{ Outgroup evaluation } & \multicolumn{3}{|c|}{ Contact intentions } & \multicolumn{3}{|c|}{ Contact self-efficacy } \\
\hline Intercept & 4.68 & & & 3.78 & & & 5.54 & & \\
\hline Positive contact & $.57(.06)^{* *}$ & .47 & .22 & $.55(.08)^{* *}$ & .42 & .17 & $.40(.07)^{* *}$ & .37 & .13 \\
\hline$F$ & \multicolumn{3}{|c|}{$78.41 * *$} & \multicolumn{3}{|c|}{$33.25^{* *}$} & \multicolumn{3}{|c|}{$32.16^{* *}$} \\
\hline$R^{2}$ & \multicolumn{3}{|c|}{.44} & \multicolumn{3}{|c|}{.25} & \multicolumn{3}{|c|}{.24} \\
\hline
\end{tabular}

$* p<.05, * * p<.001$ 
Table 6

Point estimates and confidence interviews for indirect effect of negative and positive contact with Muslim immigrants on contact intentions

towards secondary outgroups via contact intentions towards the primary outgroup (Study 3)

\begin{tabular}{|c|c|c|c|c|c|c|c|c|c|c|c|c|c|}
\hline & & \multicolumn{6}{|c|}{ Negative Contact } & \multicolumn{6}{|c|}{ Positive Contact } \\
\hline & & \multicolumn{2}{|c|}{ Total Effect } & \multicolumn{2}{|c|}{ Direct Effect } & \multicolumn{2}{|c|}{ Indirect Effect } & \multicolumn{2}{|c|}{ Total Effect } & \multicolumn{2}{|c|}{ Direct Effect } & \multicolumn{2}{|c|}{ Indirect Effect } \\
\hline & & $b(\mathrm{SE})$ & $95 \%$ CIs & $b(\mathrm{SE})$ & $95 \% \mathrm{CIs}$ & $b(\mathrm{SE})$ & $95 \%$ CIs & $b(\mathrm{SE})$ & $95 \% \mathrm{CIs}$ & $b(\mathrm{SE})$ & $95 \% \mathrm{CIs}$ & $b(\mathrm{SE})$ & $95 \%$ CIs \\
\hline & Model & & & & & & & & & & & & \\
\hline \multirow[t]{2}{*}{$\begin{array}{l}\text { Eastern European } \\
\text { Immigrants }\end{array}$} & 1 & $\begin{array}{l}-.23 \\
(.14)\end{array}$ & $\begin{array}{l}{[-5126,} \\
.0523]\end{array}$ & $.02(.12)$ & $\begin{array}{l}{[.2258} \\
.2627]\end{array}$ & $-.25(.08)$ & $\begin{array}{l}{[-.4511} \\
-.1134]^{*}\end{array}$ & $.10(.08)$ & $\begin{array}{l}{[-.0687} \\
.2639]\end{array}$ & $-.10(.08)$ & $\begin{array}{l}{[-.2565} \\
.0623]\end{array}$ & $.19(.05)$ & $\begin{array}{l}{[.1148,} \\
.3003]^{*}\end{array}$ \\
\hline & 2 & $\begin{array}{l}-.22 \\
(.12)\end{array}$ & $\begin{array}{l}{[-.4462,} \\
.0156]\end{array}$ & $-.04(.11)$ & $\begin{array}{l}{[-.2602,} \\
.1726]\end{array}$ & $-.17(.06)$ & $\begin{array}{l}{[-.3219,-} \\
.0768]^{*}\end{array}$ & $.09(.08)$ & $\begin{array}{l}{[-.0781} \\
.2493]\end{array}$ & $-.10(.08)$ & $\begin{array}{l}{[-.2553} \\
.0621]\end{array}$ & $.18(.04)$ & $\begin{array}{l}{[.1049-} \\
.2893]^{*}\end{array}$ \\
\hline \multirow[t]{2}{*}{$\begin{array}{l}\text { Indian } \\
\text { Immigrants }\end{array}$} & 1 & $\begin{array}{l}-.09 \\
(.14)\end{array}$ & $\begin{array}{l}{[-.3726,} \\
.1929]\end{array}$ & $.18(.11)$ & $\begin{array}{l}{[-.0382} \\
.4028]\end{array}$ & $-.27(.11)$ & $\begin{array}{l}{[-.5365,-} \\
.0964]^{*}\end{array}$ & $.30(.08)$ & $\begin{array}{l}{[.1370} \\
.4714]^{*}\end{array}$ & $.07(.08)$ & $\begin{array}{l}{[-.0770} \\
.2201]\end{array}$ & $.23(.06)$ & $\begin{array}{l}{[.1292-} \\
.3575]^{*}\end{array}$ \\
\hline & 2 & $\begin{array}{l}-.05 \\
(.12)\end{array}$ & $\begin{array}{l}{[-.2838} \\
.1754]\end{array}$ & $.14(.10)$ & $\begin{array}{l}{[-.0563,} \\
.3408]\end{array}$ & $-.20(.08)$ & $\begin{array}{l}{[-.3853,} \\
-.0721]^{*}\end{array}$ & $.27(.08)$ & $\begin{array}{l}{[.1112,} \\
.4415]^{*}\end{array}$ & $.06(.07)$ & $\begin{array}{l}{[-.0909} \\
.2040]\end{array}$ & $.22(.05)$ & $\begin{array}{l}{[.1174,} \\
.3348]^{*}\end{array}$ \\
\hline \multirow[t]{2}{*}{$\begin{array}{l}\text { Black African } \\
\text { Immigrants }\end{array}$} & 1 & $\begin{array}{l}-.18 \\
(.14)\end{array}$ & $\begin{array}{l}{[-.4532,} \\
.0899]\end{array}$ & $.04(.12)$ & $\begin{array}{l}{[-.2013,} \\
.2772]\end{array}$ & $-.22(.08)$ & $\begin{array}{l}{[-.4048,-} \\
.0887]^{*}\end{array}$ & $.27(.08)$ & $\begin{array}{l}{[.1073,} \\
.4262]^{*}\end{array}$ & $.09(.08)$ & $\begin{array}{l}{[-.0631} \\
.2523]\end{array}$ & $.17(.04)$ & $\begin{array}{l}{[.1022,} \\
.2711]^{*}\end{array}$ \\
\hline & 2 & $\begin{array}{l}-.12 \\
(.11)\end{array}$ & $\begin{array}{l}{[-.3454,} \\
.1036]\end{array}$ & $.02(.11)$ & $\begin{array}{l}{[-.1986,} \\
.2285]\end{array}$ & $-.14(.05)$ & $\begin{array}{l}{[-.2641,-} \\
.0545]^{*}\end{array}$ & $.26(.08)$ & $\begin{array}{l}{[.0949,} \\
4160]^{*}\end{array}$ & $.09(.08)$ & $\begin{array}{l}{[-.0658,} \\
.2524]\end{array}$ & $.16(.04)$ & $\begin{array}{l}{[.0086,} \\
.2596]^{*}\end{array}$ \\
\hline
\end{tabular}

Note: In Model 1, the IVs were tested in separate models, in Model 2 the IVs were tested simultaneously in the same model. Significant effects as indicated by the lack of a presence of a zero within the 95\% CI, are marked with an asterisk. All results are based on 5,000 bootstrapped resamples 